\title{
Role of Fathers in Early Years of Child's Life
}

\author{
Mona Minhaz Ali Jindani \& Sanober Nadeem
}

1. Human Development Program, Aga Khan University

Corresponding author::m.jindani14@gmail.com

\begin{abstract}
The study focus on investigating the perceptions and practices of fathers and its impact on children's development. It attempts to establish the effect of father's involvement in children life. Very few studies to date could be found on this subject area. In recent days, people are more learned and want to educate their selves on how they should deal their children and at the same time best practices for fathers should also be established by researches and studies. This study was done to involvement of fathers in child care as their involvement effects socio economic development of a child. Fathers are usually preoccupied in earning bread for the family however they should play their role in child carePurposive sampling was done for the purpose of this search after which focused group discussion (FGD) were conducted on 5 different locations to address all the socio economical classes of fathers. Father of a given sample were accumulated at a single place for the purpose of the research study and interviews/discussion were conducted in presence of a note taker and a principal investigator, prior consent was taken from all the fathers before the focused group discussion. According to the study it has been proved that fathers involvement had a great influence on children development. Children were good at schools and interaction with other where father's involvement was high. Usually, fathers are ideal for child but studies shows that paternal involvement has been low in comparison to maternal but this perception is changingwith time. The research identified that fathers are usually busy in earning bread for their family due to which they have fairly less stake in the child development however there is an increasing trend in fathers who understands the importance of their role in child care and child development and also they try to give maximum contribution in the upbringing of their children.
\end{abstract}

\section{KEYWORDS}

Role of fathers, Early childhood development, Parenting style, Importance of fathers, Children development

\section{ABBREVIATIONS}

FGD: Focus Group Discussion

REC: Religious Education Center

ERC: Ethical review committee.

PI: Principal investigator

ECD: Early childhood development

\section{BACKGROUND AND INTRODUCTION}

Early years are very important for children's development. This phase of development starts from conception and continue till 8 years of life In these early years children develops their utmost personality by observing and learning from environment, children also develop their social, emotional, cognitive, physical skills(Flouri,2003)

Parenting can be defined as the action includes many specific types of behavior that work individually and together which had a great influence on children and their outcomes. Parenting described as different types of behaviors of parents like aggressive, passive and assertive. Parenting means how parents deal with their child and how they control and guide to child, parenting effects on domains of development of children. Responsiveness and being demanding at the same time is defined as the best way of parenting by one of the author in his studies.

In this era, when the parenting styles have a great influence on child's development and also affects the later outcomes it becomes very important to manage these parenting styles and articulates its importance amongst the parent as this matter is of utmost importance that the parents especially the fathers realize their responsibilities in the nurture of their child. It was shown in study that authoritative and authoritarian parenting styles of mother's scores had significant correlations with children's academic achievement but on the other hand it is exposed that permissive parenting style, as well as paternal authoritative and authoritarian parenting styles showed no connections with children's academic achievement (Flouri,2003)
Author's described parenting standards, behavior, care giving practices, stimulating, supportive experiences and opportunities for learning. These parenting standards help parents to know the status of child development. For example if parents read a story with pictures so this indicates stimulating and supportive parenting standards (Boechler,2003)

From the last decade, parenting involvement has been an important topic for studies and it also effects on children socio emotional and cognitive development during early years. People show their interest in search about the father's role and the significance of father's role in children's socio emotional, academic and cognitive development. Multiple studies now working on the involvement of fathers and exploring the area day by day and various researches are now being conducted on the subject. Studies reveal that fathers involvement in early years effects on school performance and less behavior problems in children.

While reviewing various studies it was apparent that males were targeted badly by the society as 17 out of the 20 article were discussing females whereas only 3 of them were concentrating on the masculine aspect of parenting i.e. Fatherhood. Fathers should be involved in children's lives but they give minimum time or sometimes they are totally absent, so the absence of father had a significant influence on children development. Presence of father for some time doesn't means that father-child interactions were going well. Father should understand their role in children's life and its effect on children development. Multiple studies pointed out that positive involvement of fathers can lead child for betterment at different stages of development. Absence of a father converted in to neglect form and children totally neglecting by father, effects of 
which were observed on children's social behavior. ${ }^{i}$ Fathers can be involved directly or indirectly in children development. Fathers directly involve with child by one-to-one interaction in playing, reading and talking at dinner(Boechler,2003)

Study examines some possible effects of the presence and quality of parent-child interaction of fathers and father figures on the behavior of young children. Whereas the presence or absence of a father seemed to make little difference in child behavioral problems at age 4 , lower levels of aggression and depression were observed for children by age 6 .

A study suggests that the father's presence directly effects on children's social emotional development. Children with Good interaction with fathers have secured emotionally and can easily expression their feelings. Children of involved fathers have a confidence, less behavior problems, more comfortable with environment, more socially interact, etc. fathers plays a vital role in children's life. High level of care and love of father's effects on children development and friendliness behavior of fathers helps children to be more social and popular during early years. Study tells that the relationship of children with their fathers at home has an impact on parenting styles of fathers. Those mothers who have a good relationship with fathers, their children have more active, more responsive, more confident and psychologically better in early years. Those children have a good controlled on their behavior and emotional felling. A father is the role model for their children(James,2004)

Multiple studies pointed out that positive involvement of fathers can lead child for betterment at different stages of development. Fathers can be involved directly or indirectly in children development. Father's involvement as well as the parenting style that the father's adopt influences the behavioral and emotional development of the child. Fathers directly involve with child by one-to-one interaction in playing, reading and talking at dinner (Dave,2009)

Latest study suggests that now a day fathers are interested and enjoyed their role in children's life or their rearing practices. Fathers feel relax while interacting with children. Involving in children activities release stress of all the worries and its improve father-child relationship. Most of the institutes working to promote father's involvement in different activities of children (Nufer,1987)

Further studies suggest that the weak interaction or less involvement of fathers may raise the behavior problems in child at age of 6 . Studies were highlighted the importance of fathers in children behavior development in different ways(Nancy,2009)

Children in middle childhood, fathers engage in more recreational activities such as walks and outings as well as private talks. Fathers also have a strong influence on their children's gender role development and are important role models for both girls and boys. The long-term effects of fathers' direct involvement in the care of their children is evident through childhood and adolescence.(Flouri,2003)

This phenomena of "fatherhood" investigated in many countries but in our context it is lacking Moreover this research has been planned to identify the practices and perceptions of fathers about their role in children's life and this study will also pave the roadfor future research in this area.

\section{METHODOLOGY}

\section{Research Design}

Qualitative (Exploratory Research Study)

\section{Study settings \& Population}

Five ethnic communities of Karachi were selected for this study. The aim to select five areas is to capture the view of diverse population and is to get the clear picture of father role. In these areas fathers are from different financial and family background.

These five ethnic communities of Karachi, are located in Karachi central and north district, below is listed communities.

Al-Noor REC

Raimabad REC

Alyabad REC

Karimabad (Al-Haq) REC

Garden (Labella)REC

\section{Study time line}

\section{3 month (Gantt- Chart attached)}

\section{Sampling Methodology}

The purposive sampling methodology was used in this study. Only those father were present in FGD who have birth to eight years old children and they give consent to participate in the study.

The fathers were selected based on their socio economic status. A sample was selected to ensure that most socio economic classes are covered and then the same were divided into five groups for the purpose of conducting focused group discussion with them. The results acquired are according to the requirement and could be relied upon There would be 15 fathers from a single locality and 5 different locations have been identified for the purpose of FGDs.

The research was based on five focused group discussion in different centers. While talking to fathers belonging to various areas and socio economic background it was observed that the awareness about early childhood development has raised significantly amongst the parents and therefore the result of the research slightly varies from the literature.

Sample Selection:

\section{Inclusion Criteria}

Fathers of $0-8$ years old children

Father's whose children are studding in the community religious education center (REC)

Father who give consent to participate in this study

\section{Exclusion Criteria}

Fathers of disabled child (The fathers of disabled child will not be included in this study because they have different parenting styles and responsibilities for their children.)

\section{Research Tool}

\section{Focus Group Discussion Guide line}

The purpose of FGDs was to get the perception of fathers about their role in children life and to know how they manage their schedule for their children and what kind of role they play in children's life. A semi structured FGDs guideline was developed to explore father perception about their role in child care.

\section{Data Collection Methods}

After approval i.e. approval \# 2372-HDP-ERC-12 from ERC, again reminders were sent to all five different RECs to conduct the FGDs. Also permissions were already taken from the management of the religious education centers via emails and telephonic conversation.

A place was arranged to conduct the FGDs on the mentioned date and the days were communicated to the participants. Then on the day of the FGD, informed consent forms were filled by the participants. The interviewer and the participants gave brief introduction to each other, also the participants were revealed that the information will be kept 
confidential and they should remain open and truthful in the FGD and then the questions were asked from the participant to get the answer of the research question.

Permissions were given by the participants by signing the consent that the conversation will be recorded. FGDs were conducted by investigator. However a note taker and a helper were present over there.

\section{Data Analysis}

The recorded FGDs were transcribed in word document by the PI in order to analyze the data. The data was then analyzed manually but the same was not sufficient to provide appropriate validity of the results

Therefore, all the transcripts wereexported in N-vivo software, which analyzes the data for research purposes. Themes were made once the complete transcripts were entered into the software for analysis in order to analyze the data systematically over the software and have well segregated results.

After transferring the data all information was reviewed and highlighted the responses of participants according to the themes.Each FGD's was provided a unique number that will maintain the anonymity of study participants.

Also subcategories were made by the PI to further refine the analysis of the data. The general perceptions and practices of the father were analyzed once appropriate categorization of the data was made in the software.

\section{FINDINGS}

Role of Fathers:

The research identifies the perceptions of father regarding their role in their child's life and the involvement in child's activities. A father plays role of a care taker, source of affection and guidance and at the same time he is the one who keeps a keen eye over the kid to make sure he is not into some wrong activities as per the below statements.

Father's has a role in controlling the child. The child usually is concerned that father will ask you for explanation when he's back home

If father is involved the child will automatically be good in business and decision making because its father who is involved in business managing finances and decision making so their involvement will bring improvement in the child

But I would say that whatever time father will give is going to be valuable because in both the parents father is the one who have more like father like son. Fathers have a lot of impact on the daughters as well

I use to discuss religion and moral values because the kid spends much time in secular education as compare to religious education therefore I try to make him learn all this

Whenever he asks for junk food I tried to divert his attention and get him some alternatives which are healthy.

Whenever my younger child unnecessarily insist of something I used to tell him about obedience of his elder siblings and when I used to tell stories when I have to make three of them understand something.

When child learn something wrong from outside we must reprimand and if he learn something new so we must appreciate. If he don't follow my instruction I asked him to out of the home and also warn him that I will not take him out anywhere with me.
There is a certain way to guide the child, like such as my daughter has a habit of calling her friends so many times a day. We tried to make her understand once or twice but she did not have it then her mother told her that if you don't stop calling police will put your father in jail and she stopped. We should explain child along with outcomes

\section{Involvement of Fathers}

\section{Daily Practices}

Discussions then addressed technical issues in development of child's thinking ability. The study identified fathers, who are were very concern about the diet and annual checkups of children Fathers addressed some major concerns over child health practices in the below mentioned statements

I went to attend a meeting and the teacher discussed his discipline problem that his behavior is not well with his friends also he use to snatch things from other kids. Then I started asking him regularly about what he did in the whole day and then I got to know what the weakness was.

I drive my kids through and we discuss a lot of things which we see around during the drive, such as how the car runs and filling air in the tires, signboards we see on the way etc. father has a role in the mind development of the kid.

Child is like a blank paper and we are responsible to write on it, he will learn by observing you. As the idiom says, "what you saw so shall you reap'

Now days we have to make sure that the child is taking bath, cutting nails and should give them washed and clean fruits to eat and also boiled water to drink.

I think what matters is that the child should be healthy and if he eats junk food happily then we should give it him instead of feeding him bread unwillingly

Fathers Views about Admonishing Child:

I use to scold if she does anything wrong, she cries and don't talk to me then I use to realize that what I did was wrong and then I use to go to her and tell her that where she was wrong

I would rather deny that child should have some fear of father, I believe this should be the case, child shouldn't be afraid of anyone. If you try and explain things politely, no matter how naughty the child be, will surely understand and act accordingly. It depends how we deal with them.

Fear doesn't mean that GOD forbids that every time we keep scolding them etc. yes we need to be polite but keep a distance, he shouldn't know that someone is keeping an eye so that they don't do anything wrong.

Now a days people use to have 23 kids instead of 12 or 15 kids like in early times, and therefore we can give enough time to each of them. Even if they come home with small questions regarding anything, we should be having an answer for them.

I had a lot of bad habits like smoking, but I have left them all now because my child now understands that its wrong and asks question that why you do it if it's wrong. You must take some action for their sake.

Limitations of Father Role 
The study identifies some bottlenecks that have been faced by fathers in nurturing their child in day to day life.

I believe that it's us who had created all these bottlenecks in the nurture for the sake of earning money.

Non availability of fuels, blocked roads, traffic jams and no electricity, all this keeps the fathers worried and some time he scolds the kid in pressure.

I feel that I can't communicate much with my daughter not even meet with her due to my job timing.

If child demands something from me to I have to think first due to financial problems because some time I can't afford it. So parent should be educated and doing good job so they can fulfill legitimate wishes of child.

I think, limitations are the bad city conditions of city that we can't go in garden and either garden is available in your area or not and the electricity problem.

I had committed in voluntary services after my job so I reached at $10 \mathrm{pm}$ at home so I talk with my child while dinner only.

Now days it's too difficult to take out some time for children and in my case I have many social interactions and go for outing with friends after job.

I think we should not scold kids, it makes the child to lose confidence and the child won't be able to face people and will lack confidence

If I am angry with something he also gets angry and scolds me in front of Grand parents

I never buy me kids a toy gun, so that they dun do something wrong because the media has been very aggressive these days and once he saw some news about some people killed and said to his grandfather that I will hit you with a gun. I take a lot of care still the child gets to know all this

Disciplinary practices of father affecting children attitude

Father knows what field is in demand and he knows that how to guide the child in his career and we have seen financial problems therefore we know how to guide them about the field and etc.

Father is responsible for working and earning money and most of the time is least bothered about what children are doing, very few of them actually have concerns

Some time we should be polite and some time we should scold. Now a day children have been smart so they should be tackled politely

Child learns from fathers, children are actually a reflection of fathers and if father will smoke there are high chances that child will also and it would difficult to stop them from the same.

I have two daughters in nursery, I regularly play with them and the prayer they do in their schools I use to enact that with them and also we recite anthem together.

Child learns from father. Child can observe father being a powerful in the house. I am not highlighting male dominance but still whenever child have to take any decision mother always suggest that first ask your Dad, so father is playing a role of decision taker.

\section{Role of Mothers}

Mother plays a vital role in child's development because child spends most of his time with mother.

If mother is more involved, the child use to get more disciplined.

The child spend more time with their mother and there is no substitute of mothers love that is something very special and often mother ignores little mischief's of their children.

We have praised the fathers a lot but if the mothers won't have been there our presence wouldn't have mattered. Mother has an important role in all matters. Without mothers fathers wouldn't have been complete as children are more close to their mothers

If the mother is busy with household chores and watching 'star plus' she use to send her kids out to play with their friends.

In our system, mothers are always busy with house hold chores, they have to do this, that, wash cloths and etc. something is always on their minds therefore they don't get time to enjoy with their children

Mothers are ranked about fathers as they are rarely present with the children in their daily routine.

\section{Role of Family}

As per the study,family is responsible for making sure that the negative influence from the society and environment are minimized. The teachings at home give children positive development as per the below statements

The nurture of the child begins at our home in which the primary role is of the parent whereas also grandparents and other incase of combined families.

Family teaches a child moral values and bounding. The children learn to compromise and this is a continuous process.

If there are grandparents in your home they also have a role, the way we treat them the child also learns the same and the way we talk to them and our behavior, the children learns from all these as home is the first place for this.

Now as the children not get the study environment at home so we send them outside for study but we save them by providing friendly environment.

\section{Role of Environment}

The study identifies that the environment of home and society has a major role to play in children life and also social engagement of children increases, after starting school. As per the below statements

When child gets into school life he meets different people from different communities and children bring lots of question with them.

When child starts going to school, environment effects on child. No doubt teacher is there and school is the place where child learn discipline, child observe others their style of communicating, etc. because children learn by observing so there is a role of environment.

I believe environment makes a difference, environment in which the children lives have impact on him. 
If we look at the schooling systems, the children spend almost 5 to 6 hours with their teachers and friends, after getting back the kid rests for a while and again they went to REC and then to their tuitions and after REC spend time amongst friends and teachers at both the places as well.

What matter is the environment in which you live in and the people, who are around, are they educated or not etc.

First of all child spend 7 hours in school after this 1 hour in van then he come back to home take his lunch and go for sleep. After awaking up he get ready for REC and after coming back from REC he watch TV and take dinner so he spend very less time with parents.

The study identified that fathers have concerns over the friendship and teachers of the child as the child spend a lot of time with them and it should be ensured that the mentoring and companionship is of premium quality per the below statement.

Then there comes role of teacher i.e. how the teacher deals with the student and how much time teacher is giving to the student or weather some child is being ignored and may get in to complex.

In role of the friends, what kind of friend circle he has and parenting style of his friend's parents and their background and what they learn? What they do and what they discuss is important.

Environment could be a problem, if he is with some bad friends and learns something that's not good then it gets difficult to make him understand

I repeat my thing again that no matter how much you try and take your child for prayer but if friends will ask him to watch TV, he will definitely do that, surely environment have an effect.

\section{DISCUSSION}

Environment plays a vital role because children learn through observation in their early years. According to the analyzed data when child enters school life, they spend a lot of their time in social activities and therefore people who are around them like neighbor's teachers and others have an everlasting effect on children development in early year whereas increasing social activities leaves children with less time to spend at home(Flouri,2003)

Studies have shown that fathers have a great influence on children's socio emotional and behavioral development. In Pakistan, father is the main source for earning income and support financially to their families (Agha,2010)Findings shows that financial crises often causes fathers to remain busy in earning money and give financial support to family but now fathers are aware about importance of their role so they trying to manage the time and involve in child care. Studies discuss about the positive involvement of father in children's development.

Studies shows fathers play a vital role in decision making for child. Now a day city conditions are very sensitive for children and media guide children in a wrong way so at that time fathers role are important and father take all decisions for children(Marshall, 2008)

Children meet new people in the society and observe people who are around them belonging to various different communities, so they often brings home a lot questions as a results of an attempt of comparing their self with people around them(Coleman,2004)

Here the role of family starts, they are responsible to clarify all misconception of child by answering their question. Friends of child effect on children daily life because all friends come with different family background and they share everything in friend circle. Child learns many things from their friends. The friends circle of children effects on the behavior of child. The schedule of school going children is very hectic so they spend very less time at home with parents (Darling,1999)

After parents, grandparents play a major role in child's life. Grand parents teach religious things to child. Grandparents guide children according to their experiences(Besharat,2011)

Father play role as career guider and as a decision taker in children life. Fathers interact with many people in their daily life, so they know how to deal with people of different communities. They know the demand of education field so they can guide their children about their career(Aunola,2005)Fathers also guide their according to their experiences because fathers faces all financial crises so he can guide children for their business or the way to earn money in future. Child should understand the value of money. Fathers adopt many different ways to deal with children when children are insist of something unnecessarily but still most of the fathers scold child for stopping them by doing anything wrong(Campo,2008)

Now a days environment is very sensitive and we daily listen about the bad condition of the city and the bad habits adopted by youngsters so father is the only one by whom children afraid and listen their instructions very carefully. Fathers can observe child outside the house because mothers are busy with household chores. But sometimes it can be observed that Father is just for strictness who always scold child for their mistakes. Only strictness of father loses the confidence of child. Child will never speak with others confidently.

Parents are equally responsible for child nurturing. Now a day parents are very much concern about the children. Many institutions are working to spread the knowledge about the importance of ECD(Radhakrishna,2001)

Fathers are facing the some problems in nurturing the child. The family financial condition and education of parents effects lots on children development. Now a day schools and REC both are working to give the best knowledge to child but due to the uneducated fathers, child suffer in many activities. Socio cultural background is the problem for fathers in some family still father is responsible to earn money and do al outside work so fathers are just for outing where children can't go alone. After having these all problems fathers are now trying to resolve the problems and involved in daily activities and try to get rid of these problems and give the quality time to their children(Beitel,1998)

The finding of research shows that now fathers are more aware about their role and most of them are changing their perception about the male dominating society, still some father acing the same problems but all of them are trying to give quality time to their child. The changing perceptions and practices of fathers are very visible (Marshall, 2008)

\section{LIMITATIONS}

The authors acknowledge that this study has limitations. The study is based on the responses of five FGDs.

Face difficulty to gather the fathers on same place at same time.

Faced difficulty to conduct more FGDs and gather more information due to the change of the management centers.

Fathers are available only on vacant days.

Timing issue, PI should conduct the FGD during REC timings.

\section{ACKNOWLEDGMENT}

I would like to thank Ms. Sanober, Mrs Asma Makhani and $\mathrm{Mr}$ Rahim Jindani for continuous support, feedback and very helpful guidance during the discussions and meetings. Also would take the chance to thank my peers and fellows for the healthy discussions we had on the topic I have selected. 
1) Aunola, K., \& Nurmi, J. E. (2005). The role of parenting styles in children's problem behavior. Child development, 76(6), 1144-1159.

2) Boechler, V., Harrison, M. J., \& Magill-Evans, J. (2003). Father-child teaching interactions: The relationship to father involvement in caregiving. Journal of Pediatric Nursing, 18(1), 4651.

3) Nufer, H. (1987). Development of the father-child relationship. A frequently underestimated element]. Krankenpflege. Soins infirmiers, 80(2), 78.: 80 (2): 78-82.

4) Dubowitz H. (2006). Where's Dad? A need to understand father's role in child maltreatment.30, 461-465.

5) Darling, N. (1999). ED427896 1999-03-00 Parenting Style and Its Correlates. ERIC Digest.

6) Agha, A., Ajmal, F., Iqbal, A., \& White, F. (2010). Father's support and literacy-Factors associated with child mortality in Gambat, Sindh, Pakistan. JPMA. The journal of the Pakistan Medical Association, 60(2), 81 .

7) Campos R. (2008). Considerations of studying Father Involvement in Early Childhood among Latino Families. Journal of Behavioral Sciences, 30(2), 133-160.

8) Marshall D.B., English D.J., Stewart A.J. (2008) the effects of fathers Figures on child behavior Problems in families referred to child protective's services.

9) Dave s., Sherr L., Senior R., Nazareth I. (2009) Major paternal depression and child consultation for developmental and behavioral problems. Journal of General practice, 59, 180-185.

10) Hobson L., Noyes J. (2011) fatherhood and children with complex health care needs: qualitative study of fathering, caring and parenting.

11) Radhakrishna A., Bou-saada I.E., Hunter W.M., Catellier D.J., Kotch J.B. (2001) Are father surrogates a risk factor for child Maltreatment? Journal of the American Professional Society on the abuse of children, 6(4), 281-376.

12) Coleman W.L., Garfield C. (2004). Fathers and pediatrics: Enhancing Men's role in the care and Development of their children. Journal of the American Academy of Pediatrics, 113(5), 113-1406.

13) James J. H.(2004) Importance of Early Childhood Development, Encyclopedia on early childhood development, Nov, 3; 1-8

14) Nancy,D.(1999).Parenting styles and its Correlates.(217):333-1386

15) Besharat, M. A., Azizi, K., \& Poursharifi, H. (2011). The relationship between parenting styles and children's academic achievement in a sample of
Iranian families. Procedia-Social and Behavioral Sciences, 15, 1280-1283.

16) Hobson, L., \& Noyes, J. (2011). Fatherhood and children with complex healthcare needs: qualitative study of fathering, caring and parenting. BMC nursing, 10(1), 5

17) Yeung, W. J., Duncan, G. J., \& Hill, M. S. (2000). Putting fathers back in the picture: Parental activities and children's adult outcomes. Marriage \& family review, 29(2-3), 97-113.

18) Beitel, A. H., \& Parke, R. D. (1998). Paternal involvement in infancy: The role of maternal and paternal attitudes. Journal of Family Psychology, 12(2), 268

19) Agha, A., Ajmal, F., Iqbal, A., \& White, F. (2010). Father's support and literacy-Factors associated with child mortality in Gambat, Sindh, Pakistan. JPMA. The journal of the Pakistan Medical Association, 60(2), 81.

20) Campos, R. (2008). Considerations for studying father involvement in early childhood among Latino families. Hispanic Journal of Behavioral Sciences, 30(2), 133-160..

21) Marshall, D. B., English, D. J., \& Stewart, A. J. (2001). The effect of fathers or father figures on child behavioral problems in families referred to child protective services.Child Maltreatment, 6(4), 290-299.

22) Otani, K., Suzuki, A., Shibuya, N., Matsumoto, Y., \& Kamata, M. (2009). Dysfunctional parenting styles increase interpersonal sensitivity in healthy subjects.The Journal of nervous and mental disease, 3(12), 938-941. 